\title{
Ringwoodite rim around olivine core in shock-induced melt- vein of GRV 022321 chondrite: Transformation kinetics of olivine to ringwoodite
}

\author{
Zhidong Xie ( $\nabla$ zhidongx@nju.edu.cn ) \\ Nanjing University https://orcid.org/0000-0002-4538-6440 \\ Thomas G. Sharp \\ Arizona State University - Tempe Campus: Arizona State University \\ Shuhao Zuo \\ Nanjing University \\ Xiaochun Li \\ Nanjing University
}

Research article

Keywords: Olivine, Ringwoodite, Rim, Shock melt vein, Mg-Fe interdiffusion, Phase transformation, Long-range diffusion, Grain-boundary diffusion

Posted Date: September 16th, 2021

DOI: https://doi.org/10.21203/rs.3.rs-885625/v1

License: (c) (1) This work is licensed under a Creative Commons Attribution 4.0 International License. Read Full License 


\section{Abstract}

Here we report the natural occurrence of the ringwoodite rims around olivine cores in shock-induced melt veins of the Antarctic chondrite GRV 022321. Electron microprobe analysis (EMPA), Raman spectroscopy, Scanning electron microscopy (SEM) and Transmission electron microscopy (TEM) were used to examine the sample to better elucidate the mechanisms of transformation of the olivine to ringwoodite and Fe-Mg partitioning in olivine under the shock. The GRV 022321 is an L6 chondrite with a network of black veins enclosing abundant olivine host-rock fragments. Some of the enclosed fragments ranging from $5 \mu \mathrm{m}$ to $100 \mu \mathrm{m}$ in size have bright rims up to $20 \mu \mathrm{m}$ wide, and a dark core under reflected light and backscatter electron imaging. Raman spectroscopy reveals that rims are made of ringwoodite, and cores are predominantly olivine. EMPA data show the ringwoodites in rims are richer in $\mathrm{Fe}\left(\mathrm{Fa}_{46}\right)$ than the olivine cores $\left(\mathrm{Fa}_{10}-\mathrm{Fa}_{23}\right)$. The olivine cores have variable contrast in BSE images with the heterogeneities in fayalite content $\left(\mathrm{Fa}_{10}\right.$ to $\left.\mathrm{Fa}_{23}\right)$ and a branching network of low-Fa olivine. FIB-TEM observations reveal that the ringwoodite rims are polycrystalline with crystallite sizes from $200 \mathrm{~nm}$ to $800 \mathrm{~nm}$, while the olivine cores are also polycrystalline, but with smaller crystallites from $100 \mathrm{~nm}$ to $200 \mathrm{~nm}$. Based on observation, we conclude that the original $\mathrm{Fa}_{23}$ olivine transformed to $\mathrm{Fa}_{10}$ olivine and $\mathrm{Fa}_{46}$ ringwoodite by a solid-state diffusion-controlled growth mechanism during shock, and the branching network of low-Fa olivine acted as long-range(up to 10 $\mu \mathrm{m}$ )high-diffusion pathways for grain-boundary Fe-Mg interdiffusion through highly deformed nano-crystalline olivine to accommodate the diffusion-controlled growth of ringwoodite.

\section{Introduction}

Ringwoodite $(\mathrm{MgFe})_{2} \mathrm{SiO}_{4}$, the spinel-structured high-pressure polymorph of olivine, is common in and around shock-melt veins in highly shocked chondrites (Binns et al., 1969; Chen et al., 1996; Mason et al., 1968; Price et al., 1979; Putnis and Price, 1979; Sharp et al., 2015; Xie et al., 2002; Xie and Sharp, 2004; Xie et al., 2006a). Ringwoodite forms by crystallization from shock melt, along with other high pressure minerals such as majorite, akimotoite or bridgmanite (Sharp et al., 1997,Xie and Sharp, 2004; Xie et al., 2006b), and it forms by the solid-state transformation of host-rock olivine fragments entrained in the shock melt veins and pockets (Binns et al., 1969, Chen et al., 1996). The microstructures preserved in transformed olivine provide clues to the mechanisms of solid-state reactions. A summary of the high-pressure mineralogy of shocked meteorites, including a detailed list of occurrence and references, can be found in a paper by Tomioka and Miyahara (2017). This contribution is dedicated to the memory of Professor Ahmed El Goresy, who made many contributions to the field of shocked meteorites and the mechanisms of shock-induced phase transitions (Chen et al, 2004, Miyahara et al., 2008ロMiyahara et al 2016).

Generally, in shocked chondrites, ringwoodite after olivine has the same or nearly the same chemical composition as the host olivine, but in some cases, the ringwoodite occurs as Fe-rich (ahrensite-rich) rims on more forsterite-rich olivine. Such ringwoodite rims were found during the classification research of Chinese Antarctic chondrites Grove Mountains (GRV) 022321 (Xie et al., 2012), 052049 and 052082 (Feng et al., 2011). Ringwoodite reaction rims have been produced in static highpressure experiments designed to measure ringwoodite growth rates during solid-state transformation (Kershhofer et al., 1996, 1998, 2000; Diedrich et al., 2009; Du Frane et al. 2013). Other high-pressure reaction rims have been reported in a variety of heavily shocked (S6) meteorites including wadsleyite rims on ringwoodite in ALH78003 (Ohtani et al. 2006), and ringwoodite rims on wadsleyite in Peace River (Miyahara et al., 2008). The wadsleyite rims around ringwoodite cores in ALH78003 were interpreted as the result of solid-state transformation with long-range Mg-Fe interdiffusion (Ohtani et al., 2006). The ringwoodite rims around wadsleyite cores in Peace River were interpreted as the result of melt crystallization (Miyahara et al., 2008). The ahrensite-rich ringwoodite rims on Fa-poor olivine in GRV 052049 were interpreted as product of melt crystallization (Feng et al., 2011), whereas similar features in Dofar 922 (Badjukov et al, 2005) and Asuka 09584 (Pittarello et al. 2015) were interpreted as the result of solid-state transformation and local chemical equilibrium during shock.

The ahrensite-rich ringwoodite rims in samples such as GRV 022321 L6 chondrite are important because they provide insight into the mechanisms and kinetics of the olivine-ringwoodite transformation during shock. The high-pressure minerals in shock-melt veins provide important constraints on melt-vein crystallization, shock conditions and the duration of shock event

Page 2/18 
(Xie et al., 2006b; Xie et al., 2008). Thermal modelling of melt-vein quench at high pressure has been used to constrain the minimum durations of shock events in Martian meteorites and L chondrites (Langenhorst and Poirier, 2000; Xie et al., 2006b; Hu and Sharp, 2017). Similarly, growth rates for high-pressure minerals, combined with crystallite sizes in polycrystalline aggregates (Ohtani et al., 2004; Xie and Sharp, 2007; Ma et al., 2016) and chemical zoning combined with diffusion rates (Beck et al., 2005, Chen et al., 2004) have been has been used to constrain shock duration. However, the use of kinetic data, including growth rates and diffusion rates, one must understand the mechanisms active in the sample and the appropriate experimental data for the given pressure-temperature conditions. For example, the rate of an olivine transformation that does not change chemical composition, known as interface-controlled growth, is generally faster than a transformations that changes composition and requires long-range chemical diffusion. The latter, which is controlled by the rate of diffusion between reactants and products, known as diffusion-controlled growth, is generally slower than interface controlled growth (Kerschhofer et al., 2000; Kerschhofer et al., 1996; Sharp and DeCarli 2006; Xie et al., 2008). Therefore, any constraint on shock duration derived from growth-rate kinetics requires a detailed understanding of the transformation mechanisms active during shock.

Here we report results of a detailed analysis of the mineralogy, chemistry and microstructures of partially transformed olivines in the Antarctic chondrite GRV 022321. These olivines have distinct ahrensite-rich ringwoodite rims and complex internal microstructures that have only been reported in a subset of shocked L chondrites, including GRV 022321, GRV 052049 (Feng et al. 2011), Asuka 09584 (Pittarello et al. 2015) and Dofar 921 (Badjukov et al, 2005). The purpose of this study is to determine the mechanisms of transformation and the long-range $\mathrm{Mg}$-Fe interdiffusion that produced the ahrensite-rich ringwoodite rims in GRV 022321 and similar samples.

\section{Sample And Methods}

GRV 022321 is an Antarctic chondrite with weight of $2.16 \mathrm{~g}$, collected by Chinese Antarctic Research Expedition Team in January 21st of 2003 in Grove (GRV) Mountains, located in the latitude of S72 $46^{\prime} 30^{\prime \prime}$ and longitude of E75 $19^{\prime} 45^{\prime \prime}$. The sample, which is owned by and curated at the China Polar Research Institute Center (PRIC), was classified as an L6 S5 W2 ordinary chondrite (Weisberg et al., 2009). One polished thin section was provided for research by the PRIC.

The polished thin section was analyzed using a JEOL JXA8100M electron microprobe in the State Key Laboratory for Mineral Deposits Research at Nanjing University. Sample mineralogy, shock-vein textures and transformation microstructures were investigated using backscattered electron (BSE) imaging. Quantitative X-ray microanalysis was done by wavelengthdispersive X-ray spectroscopy (WDS). For WDS we used a $15 \mathrm{keV}$ beam energy, $20 \mathrm{nA}$ beam current, a beam diameter $<2 \mu \mathrm{m}$, and collection times 20 s for each element and 10 s for background. The mineral calibration standards used were amphibole for $\mathrm{SiO}_{2}, \mathrm{MgO}$, and $\mathrm{CaO}$, and olivine for $\mathrm{FeO}$. Additional BSE imaging was done on the Zeiss Supra 55 FEG-SEM at Nanjing University, using a beam energy of $15 \mathrm{keV}$.

Micro-laser Raman spectroscopy is powerful for identifying high pressure phases in meteorites (Acosta-Maeda et al., 2013). High-pressure mineral polymorphs were identified by Raman spectroscopy, using a Renishaw a RM2000 Raman system at Nanjing University, and a LabRAM HR Evolution Raman system at Peking University. The laser wavelengths used were $514 \mathrm{~nm}$ and $532 \mathrm{~nm}$, respectively. Raman collection times were 30s for most points, 120 s for some points to get more signal, and $10 \mathrm{~s}$ for mapping. The spectral peak positions were calibrated using a quartz $\left(520 \mathrm{~cm}^{-1}\right)$ standard.

Features of interest for TEM analysis were selected for FIB lift out from EMPA BSE images. The FEI Nova 200 NanoLab FIB/SEM at Arizona State University (ASU) was used to cut and thin FIB foils for TEM analysis. A platinum strip was deposited across the feature of interest on the sample in order to prevent the gallium implantation contamination and sputtering damage to the features of interest. Foil blocks were excavated, cut free, and lifted out then welded to a cupper TEM half grid. The blocks were then thinned down to $200 \mathrm{~nm}$ using intermediate aperture (ion beam current 0.3-1 nA at $30 \mathrm{keV}$ ), and further polished the foil down to $100 \mathrm{~nm}$ thickness using fine gallium ion beam with current 10-50 pA. The long thin foil is fragile, therefore, only $5 \mu \mathrm{m}$ part of $10 \mu \mathrm{m}$ long slice was thinned down to $100 \mathrm{~nm}$ which contain the rim and core part. TEM data were 


\section{Results}

\subsection{Overview features of shock-induced melt-vein}

The major minerals in GRV 022321 chondrite include olivine $\left(\mathrm{Fa}_{23}\right)$, pyroxene $\left(\mathrm{Wo}_{21}\right)$,plagioclase, troilite, and minor unknown minerals. Olivine and pyroxene grains show abundant shock-induced irregular and planar fractures (Fig. 1a). Most grains also show pervasive mosaicism as indicated by a pronounced irregular optical extinction under cross-polarized light (Fig. 1a). Most plagioclases turn into isotropic maskelynites and few of them show flow features indicative of normal glass (Stöffler et al., 1991). Olivine with strong mosaicism and abundant maskelynites indicate a shock grade of S5 (Weisberg et al., 2009).

Three nearly parallel melt veins occur in the thin section studied. Most parts of the melt vein are narrow with width up to10 $\mu \mathrm{m}$ with few entrained host-rock fragments (Fig. 1), while some parts of melt vein transition into much wider vein (Fig. 1b), or melt pockets with width up to $200 \mu \mathrm{m}$ wide (Fig. 1d), with abundant host-rock fragments (Fig. 1). The melt veins are opaque under transmitted light (Fig. 1a); while in reflected light and BSE imaging they show a fine-grained matrix with bright rounded metaltroilite blebs dispersed in a matrix of quenched silicate melt surrounding rounded host-rock fragments. Such matrix features are similar to that of the shock-induced melt veins in other chondrites, such as in Tenham, Umbarger, Roy, etc (Xie et al., 2006a, b).

The difference is that the olivine host rock fragments in GRV 022321 chondrite have one striking bright Fe-rich rim around darker Fe-less core (Fig. 1c and 1d). Later Raman and TEM data indicate the bright rim consisting of Fe-rich ringwoodite, and darker core mainly consisting of crystalline olivine.

\subsection{SEM and Raman observation of rimmed olivine fragments}

Back scattering electron (BSE) images of olivine host fragments show Fe-rich bright ringwoodite rims surround Mg-rich dark olivine (Fig. 1c and 1d). These rim textures are different from ringwoodite textures reported in our previous studies of Tenham, Umbarger and Roy chondrites, which have rounded ringwoodites with uniform BSE contrast and therefore uniform ahrensite ( $\mathrm{Fe}_{2} \mathrm{SiO}_{4}$-spinel) content (Xie and Sharp, 2007; Xie et al., 2006a, b). The olivine fragments in the shock melt of GRV 022321 generally range from $5 \mu \mathrm{m}$ to $30 \mu \mathrm{m}$ wide with some grains up to $100 \mu \mathrm{m}$ (Fig. $1 \mathrm{~b}$-d). The ahrensite-rich ringwoodite rims are typically $5 \mu \mathrm{m}$ thick, but can be as thick as $20 \mu \mathrm{m}$ (Fig. 1c and 1d). Transformed olivines that are less than $5 \mu \mathrm{m}$ in diameter are pure ringwoodite with uniform composition with no evidence of an Fe-rich rim or Mg-rich core (right upper corner in Fig. 1b and d). These imply that complete transformation of small olivine fragments produces homogeneous ringwoodite aggregates.

The partially transformed olivine host fragments with ahrensite-rich ringwoodite rims have distinct non-uniform chemical zoning. The ringwoodite rims have a uniform BSE contrast implying that a homogenous ahrensite content in the ringwoodite (Fig. 1 and Fig. 2). On average, the olivine cores have fayalite contents similar to the untransformed olivines that occur outside the shock melt. However, the fayalite content ( $\mathrm{Fa}$ ) of the olivine drops significantly with distance toward the ringwoodite rim, resulting in darker contrast in the BSE images.

Although the ringwoodite rims have smooth outer edges contacting with melt-vein matrix, the ringwoodite rims have very irregular interfaces with the olivine inside the rim. These irregular interfaces are crosscut by dark channels radiated from inside core (Fig. 1d). The lighter patches inside of the core is full of narrower dark channels. The BSE contrast variations in core part which indicating fayalite contents, display a complex pattern of dark branching features surrounding lighter islands of brighter which are more fayalite-rich olivine (Fig. 1d, Fig. 2c). Regions of fayalite rich islands are not necessarily in the center of the olivine grain but may be anywhere inside the dark outer rim of olivine (Fig. 1d). 
We use single point Raman data and scanning Raman mapping data to identify the phases of rim and inside core of host rock fragments and surrounding matrix mineral phases. In general, Raman data reveal that the rim has strong ringwoodite (rw) signature, and the core are dominated by olivine (ol). Seven Raman data were obtained from brighter rim and dark-gray center core of one $20 \mu \mathrm{m} \times 30 \mu \mathrm{m}$ grain shown in Fig. 2a. Raman spectra of point 1 and 2 located on bright rim (Fig. 2a) have distinct $788 \mathrm{~cm}^{-1}$ and $843 \mathrm{~cm}^{-1}$ peaks, which are characteristic peaks for ringwoodite (Fig. 2b). The data of point 5 and 6 also on rim give ringwoodite signatures mixing some olivine signatures suggesting that some signals from nearby olivine. Raman data of point 4 located inside core have peaks at $822 \mathrm{~cm}^{-1}$ and $855 \mathrm{~cm}^{-1}$ (Fig. 2b), which are characteristic strong peaks for olivine. Raman data of point 3 and 7 also located inside the core show the same olivine peaks with weak ringwoodite peaks at 788 $\mathrm{cm}^{-1}$ and $843 \mathrm{~cm}^{-1}$ (Fig. 2b), indicating a mixture of a small amount ringwoodite with olivine.

Raman mapping and point spectra show the distribution of minerals in a partially transformed olivine and the surrounding shock-vein (Fig. 2). The rims on the partially transformed olivine grains consist of ringwoodite while the dark cores of the grains are predominantly composed of olivine (Fig. 2d). The Raman data collected on the LabRAM HR (Fig. 2d) have a higher signal to noise ratio and clearly show strong peaks for ringwoodite in the rim, olivine in core and a small amount of wadsleyite near the ringwoodite rim. The spectra adjacent to the bright rim (point 2 in Fig. 2c) represent a mixture of olivine plus ringwoodite, and the spectrum from point 5 , near the ringwoodite rim, is pure wadsleyite. Although collected with the same laser power and duration, the wadsleyite spectrum is much weaker than the ringwoodite and olivine spectra, which suggests less wadsleyite formed compared to the ringwoodite. Raman mapping results shown in Fig. $2 \mathrm{c}$ show that the melt-vein matrix surrounding host fragments contains akimotoite and ringwoodite (Fig. 2c). The dark elongated crystals are interpreted to be akimotoite, based morphology and the low BSE contrast, whereas the brighter interstitial grains are inferred to be ringwoodite. However, the shock-vein mineralogy is not uniform. The granular texture near the vein edge (Fig. 1c), farther from host rock fragments, suggests a majorite bearing assemblage.

\subsection{EMPA composition data across one rimmed olivine host fragment}

EMPA data confirm that the ringwoodite in rim is richer in Fe-ringwoodite (ahrensite - Ah) than the olivine in core is rich in fayalite (Fa). For simplicity, we will refer to the composition of olivine and ringwoodite in terms of fayalite (Fa) content. The composition of host olivine is homogenous $\mathrm{Fa}_{23}$, which is consistent with $\mathrm{L}$ chondrite classification. The bright rim apparently has higher Fe content and more homogenous than the dark core (Fig. 2a and 2c). The core is heterogeneous with a variable BSE contrast (Fig. 2c), indicating variable Fa contents. Fayalite values from rim to core of one olivine fragment range from 48 to 9 mole \% (Fig. 3, and Table 1). The outer rim has highest Fa value of 48, and the inside darker areas with much lower Fa value, with lowest point as 9 . The Fa value of rim ranges from 44 to 48 with average of 46 . The average value of Fa from core part is 15, ranging from 10 to 23 . The Fa values decrease from 23 from core center down to 10 near the boundary between dark core and bright rim. The Fa value jumps sharply from 9 or10 to 44 or 46 from dark core to bright rim. There are two points in core with Fa value of 23 same as Fa value of host rock, which is also the highest Fa value in core. 
Table 1

EMPA analysis of one olivine fragment in the melt vein of GRV 022321 chondrite shown in Fig. 3

\begin{tabular}{|llllllllllll|l|}
\hline & ol-h(6) & rw-1 & ol-2 & ol-3 & ol-4 & ol-5 & ol-6 & ol-7 & ol-8 & rw-9 & rw-10 \\
\hline $\mathrm{CaO}$ & 0.01 & 0.05 & 0.05 & 0.03 & 0.02 & 0.03 & 0.03 & 0.01 & 0.04 & 0.04 & 0.17 \\
\hline $\mathrm{MgO}$ & 39.68 & 25.80 & 49.11 & 48.06 & 40.63 & 43.47 & 40.59 & 47.91 & 50.23 & 26.46 & 25.13 \\
\hline $\mathrm{FeO}$ & 21.60 & 38.74 & 10.14 & 12.24 & 21.12 & 16.82 & 21.28 & 12.23 & 8.45 & 37.81 & 40.77 \\
\hline $\mathrm{Al2O3}$ & 0.00 & 0.19 & 0.02 & 0.02 & 0.00 & 0.00 & 0.01 & 0.00 & 0.02 & 0.25 & 0.39 \\
\hline $\mathrm{SiO2}$ & 38.86 & 35.81 & 40.51 & 40.82 & 39.02 & 39.40 & 39.00 & 40.87 & 41.29 & 36.00 & 35.79 \\
\hline Total(wt\%) & 100.15 & 100.59 & 99.83 & 101.17 & 100.79 & 99.72 & 100.90 & 101.02 & 100.03 & 100.55 & 102.24 \\
\hline $\mathrm{CaO}$ & 0.01 & 0.05 & 0.05 & 0.03 & 0.02 & 0.03 & 0.02 & 0.01 & 0.04 & 0.04 & 0.17 \\
\hline $\mathrm{MgO}$ & 50.95 & 36.00 & 59.88 & 58.37 & 51.65 & 54.77 & 51.56 & 58.29 & 60.73 & 36.78 & 34.77 \\
\hline FeO & 15.56 & 30.32 & 6.94 & 8.34 & 15.06 & 11.89 & 15.17 & 8.35 & 5.73 & 29.48 & 31.64 \\
\hline Al203 & 0.00 & 0.10 & 0.01 & 0.01 & 0.00 & 0.00 & 0.00 & 0.00 & 0.01 & 0.14 & 0.22 \\
\hline SiO2 & 33.47 & 33.52 & 33.13 & 33.25 & 33.27 & 33.31 & 33.24 & 33.36 & 33.49 & 33.56 & 33.21 \\
\hline Total(mol) & 100 & 100 & 100 & 100 & 100 & 100 & 100 & 100 & 100 & 100 & 100 \\
\hline Fa & 23 & 46 & 10 & 13 & 23 & 18 & 23 & 13 & 9 & 44 & 48 \\
\hline
\end{tabular}

Note: ol-h(6): 6 analyses of host olivines outside of the melt vein. ol: olivine, rw: ringwoodite. The other 10 data represent ten analyses across one grain shown in Fig. 3.

\subsection{TEM observations of nano-crystalline host-rock fragments}

One TEM sample was prepared by FIB-SEM dual beam technique. FIB-SEM combining with a sample-retrieval micromanipulator system enables us to make a site-specific thin foil for TEM analysis. The final FIB slice is $5 \mu \mathrm{m}$ long and 2 $\mu \mathrm{m}$ wide with a thickness of $\sim 100 \mathrm{~nm}$ (Fig. 4a). Our FIB slice includes little part of melt vein matrix in down tip, and ringwoodite rim, and olivine inside core (Fig. 4a). TEM data are consistent with the results of Raman and EMPA. The TEM result confirmed the core part mainly consists of olivine grain, with size up to $200 \mathrm{~nm}$ (Fig. $4 \mathrm{e}$ and f). The olivine grains are randomly orientated,and clean and free of dislocation. Rim part consists of ringwoodite grains with distinct characteristic stacking faults (Fig. $4 \mathrm{f}$ and g), which are common in solid-state transformed ringwoodite (Chen et al., 1996; Xie and Sharp, 2004,2007 ). The size of rim ringwoodite grains is up to $500 \mathrm{~nm}$, bigger than olivine grain in core. TEM-EDS analyses also show the ringwoodite grains in rim part are rich in Fe.

\section{Discussion}

\subsection{High-pressure minerals and shock P-T conditions}

Host-rock olivine fragments with reaction rims are entrained host-rock fragments in the shock-melt veins of GRV 022321 and therefore experienced the same shock pressure history and similar temperatures to the quenched shock melt. Because S6 shock veins quench rapidly at high pressure, their crystallization assemblages provide constraints on crystallization pressure and therefore shock pressure history of the sample. If the sample quenched in the isobaric zone of the impact, much of the shock vein crystallization would have occurred during a period of constant equilibrium shock pressure (Xie et al., 2006a, Fritz et al. 2017), the crystallization pressure is the equilibrium shock pressure. For samples from outside of the isobaric zone, the crystallization assemblage records the quench path during decompression (Hu and Sharp, 2017). The crystallization assemblage in GRV 022321 is very similar to those reported in previous studies (Xie and Sharp, 2004; Xie et al., 2006a, b; Sharp and DeCarli, 2006, Tomioka and Miyahara, 2017), consisting of akimotoite plus ringwoodite near the host fragments 
and equant majorite plus magnesiowüstite in other areas (Fig. 1c; Fig. 1d; Fig. 2c). These mineral assemblages provide a crystallization pressure of around 18-23 GPa, which provides a reasonable estimate of the shock pressure. Metastable akimotoite adjacent to inclusions (Fig. 1d) and vein edges suggest very rapid quench of the shock vein edge from heat loss to the solid fragments and host rock (Hu and Sharp, 2017).

\subsection{Diffusion-controlled growth and Fe partitioning}

In S6 shocked chondrites, such as GRV 022321, the high-pressure minerals, such as ringwoodite after olivine, only occur in and directly adjacent to shock melt because the shock veins are the only part of the sample hot enough to promote solid-state polymorphic transformations (Xie et al., 2006b; Sharp and De Carli 2006; Pittarello, et al., 2015). High temperatures during shock, rather than local pressure spikes, are essential for polymorphic phase transformations to occur on the relatively short time scale of an impact event (Xie et al., 2006a, b; Sharp and DeCarli, 2006). In the shock-induced melt vein of GRV 022321, entrained olivine fragments are in contact with the quenched shock melt that was above the liquidus temperature of 2300$2400 \mathrm{~K}$ during shock at 18-23 GPa (Xie et al, 2006a; Hu and Sharp, 2017). The smooth rims on the initially angular host rock fragments (Figs. 1 and 2) suggest local melting of the fragment rims in a liquid that is hotter than liquidus temperature of the rock. Because the transformation of olivine is strongly temperature dependent, it is also size dependent. Fragments less than $5 \mu \mathrm{m}$ in size are completely transformed to ringwoodite of uniform composition $\left(\mathrm{Fa}_{27}\right)$ whereas the larger fragments are partially transformed with Fe-rich ringwoodite rims and complex internal microstructures and chemical heterogeneities. The partial transformation of large fragments up to $100 \mu \mathrm{m}$ across (Fig. 1b) may be a result of thermal gradients within the fragments, where rims are sufficiently hot to drive rapid polymorphic transformation and local olivine-ringwoodite equilibration.

The ringwoodite rims on olivines within the shock veins are the result of partial solid-state transformation. The olivine cores are anisotropic and show interference colors and mosaicism, indicating deformed but intact remnant olivine. EMPA point analyses show that some parts of the olivine cores retain the original $\mathrm{Fa}_{23}$ composition of the host olivine (Fig. 3). The Raman spectra collected from the olivine clasts indicate predominately olivine in the cores, ringwoodite in the rims and minor wadsleyite adjacent to the rims (Fig. 2), indicating partial transformation of olivine to ringwoodite and minor wadsleyite, with no evidence of melting. The solid-state transformation mechanism interpreted here is in contrast to the crystallization of ringwoodite and wadsleyite from melted olivine proposed by Miyahara et al. 2008 and Feng et al. 2011. The rim features seen here in GRV 022321 are very similar to those in GRV 052049, which were interpreted as products of melt crystallization (Feng et al., 2011). Our observation of $\mathrm{Fa}_{46}$ ringwoodite rims in contact with $\mathrm{Fa}_{10}$ olivine is consistent with local equilibrium and FeMg partitioning (Fig. 5).

The Fe-Mg partitioning between olivine cores and ringwoodite rims indicates diffusion-controlled growth of ringwoodite. The ringwoodite rims, with 46 mole \% fayalite $\left(\mathrm{Fa}_{46}\right)$ content are in direct contact with $\mathrm{Fa}_{10}$ olivine. The sharp difference in fayalite component at the olivine-ringwoodite interface $\left(\mathrm{Fa}_{10} \mathrm{vs}\right.$. $\left.\mathrm{Fa}_{46}\right)$ is approximately the same as the width of the olivineringwoodite two-phase loop in the P-X phase diagram (Fig. 5), which supports our interpretation of a solid-state reaction of $\mathrm{Fa}_{23}$ olivine to $\mathrm{Fa}_{46}$ ringwoodite plus stable $\mathrm{Fa}_{10}$ olivine. This implies a local chemical equilibrium between $\mathrm{Fa}_{10}$ olivine and $\mathrm{Fa}_{46}$ ringwoodite at the olivine-ringwoodite interface, which has a lower Gibbs Free Energy than $\mathrm{Fa}_{23}$ olivine. In order for the $\mathrm{Fa}_{46}$ ringwoodite to grow, it must exchange $\mathrm{Mg}$ for Fe with the olivine core by Fe-Mg interdiffusion. The rate of ringwoodite growth is therefore diffusion controlled. Similar Fe-rich ringwoodite rims have been reported in the Dofar 922 L6 chondrite by Badjukov et al (2005) and in Asuka 09584 by Pittarello et al. (2015). In both of these studies, the transformation mechanism was also inferred to be solid-state, diffusion-controlled growth, involving local equilibrium partitioning at high pressure. The obvious difficulty with these interpretations is the need for long-range Fe-Mg interdiffusion during the shock pulse.

The local equilibrium between olivine and ringwoodite suggests a lower pressure than that inferred from shock-melt crystallization. Experimental olivine-ringwoodite equilibrium data is not available at temperatures in excess of $1600^{\circ} \mathrm{C}$, but based on experiments of Katsura and Ito (1989), the equilibrium shifts by about $0.4 \mathrm{GPa} / 100^{\circ} \mathrm{C}$. Assuming a transformation temperature of 1800 to $2000^{\circ} \mathrm{C}$ would imply a pressure of approximately 14 to $15 \mathrm{GPa}$. This estimate is lower that the $18-23$

Page 7/18 
GPa pressure range inferred from melt vein crystallization and may reflect decreasing pressure during the transformation. The $\mathrm{Fa}_{23}$ olivine fragments entrained in the super-liquidus silicate melt were metastable relative to ringwoodite $\left(\mathrm{Fa}_{46}\right)$ and olivine $\left(\mathrm{Fa}_{10}\right)$ and began reacting along the olivine rims. The partitioning of fayalite content between olivine and ringwoodite resulted in diffusion controlled growth with the growth rate determined by the rate of Fe-Mg interdiffusion in the olivine. The limited presence of wadsleyite suggests that the pressure was below olivine-wadsleyite equilibrium (Fig. 5).

\subsection{Long-range Fe-Mg interdiffusion}

The solid-state diffusion-controlled growth of ringwoodite rims required long-range Fe-Mg interdiffusion over distances on the order of $10 \mu \mathrm{m}$. Partially transformed olivines have distinct variations in BSE contrast that correlates with the varying fayalite content from fayalite-poor $\left(\mathrm{Fa}_{10}\right)$ at the olivine-ringwoodite interface to $\mathrm{Fa}_{23}$-olivine fragments in the cores (Fig. 1-3). To investigate the rates of interdiffusion needed to explain these observations, we did a simple diffusion calculation using the profile illustrated in Fig. 3. Points 7 and 8 in that profile are separated by $5.6 \mu \mathrm{m}$ and have a difference in fayalite content of 4 mole \%. Assuming that the diffusion occurred within one second, which is similar to the estimates of shock duration from melt-vein quench calculations in L chondrites (Xie et al. 2007, Sharp et al 2015, Hu and Sharp, 2017), we calculate an Fe-Mg interdiffusion coefficient based on simple equation of $D=C^{\star} X^{2} / t$. In this equation, $X$ is diffusion distance in meters $\left(5.6 \times 10^{-}\right.$ $\left.{ }^{6}\right), C$ is molar difference in Fa content (0.04) and t is duration in seconds (1s). Our calculated value is $D_{M g-F e}$ is $7.9 \times 10^{-10}$ $\mathrm{m}^{2} / \mathrm{s}$, which implies very rapid Fe-Mg interdiffusion in olivine during the reaction.

To evaluate possible diffusion mechanisms, we compare our calculated diffusion coefficient to high-pressure Mg-Fe interdiffusion coefficients for olivine derived from published diffusion data (Chakraborty, 2010; Chakraborty et al., 1999; Farber et al., 2000). There are three diffusion mechanisms or diffusion domains to describe Mg-Fe inter-diffusion in olivine: 1) the purely intrinsic domain, at very high temperatures, which only depends and $\mathrm{P}$ and $\mathrm{T}$;2) the metal extrinsic domain at intermediate temperatures, which depends on $\mathrm{P}, \mathrm{T}$ and $\mathrm{fO}_{2}$, but not on the concentration of trace elements, and 3 ) the purely extrinsic domain at $\mathrm{T}$ below $800^{\circ} \mathrm{C}$, where diffusion depends on $\mathrm{P}, \mathrm{T}$ and the concentration of trace elements (Chakraborty, 2010). The published results for Mg-Fe interdiffusion in olivine correspond to the metal extrinsic domain at intermediate temperatures. The equation for the interdiffusion coefficient $\mathrm{D}_{\mathrm{Mg}-\mathrm{Fe}}$, can be written as:

$\mathrm{D}_{\mathrm{Mg}-\mathrm{Fe}}=\mathrm{D}_{0} \exp \left(\left(-\Delta \mathrm{H}-\mathrm{P} \Delta \mathrm{V}^{*}\right) / \mathrm{RT}\right)$.

We use the equation for low $\mathrm{O}$ fugacity because the shock vein contains Fe-Ni-S metallic liquid, which quenches to Fe-Ni metal and troilite, and magnesiowüstite. We selected $\mathrm{D}_{0}=8.91 \times 10^{-10} \mathrm{~m}^{2} / \mathrm{s}, \Delta \mathrm{H}=220000 \mathrm{~J} / \mathrm{mole}$ (Chakraborty, 2010). Because the rapid transformation of olivine requires very high temperatures, we use an activation volume $\Delta \mathrm{V}^{\star}$ of $5.4 \times 10^{-6} \mathrm{~m}^{3} / \mathrm{mol}(\mathrm{Farber}$ et al., 2000).

$\log \mathrm{D}=-8.91-\left(220000+\left(\mathrm{P}-10^{\wedge} 5\right)\right) \star 5.4^{\star} 10^{\wedge}(-6) / 2.303 \mathrm{RT}+3\left(\mathrm{X}_{\mathrm{Fe}}-0.1\right)$

We calculated $\mathrm{D}_{\mathrm{Mg}-\mathrm{Fe}}$ at temperatures ranging from $1473 \mathrm{~K}$ to $2273 \mathrm{~K}$ at the pressure of 15 and $20 \mathrm{GPa}$ to approximate the conditions of olivine transformation in GRV 022321 . Our calculated values for $20 \mathrm{GPa}$ are $\mathrm{D}_{\mathrm{Mg}-\mathrm{Fe}}=10^{-22.5} \mathrm{~m}^{2} / \mathrm{s}$ at $1473 \mathrm{~K}$, $10^{-19.5}$ at $1873 \mathrm{~K}$, and $10^{-17.6}$ at $2273 \mathrm{~K}$. These values are far too low to explain the $\mathrm{Mg}$-Fe interdiffusion observed in our sample. At $15 \mathrm{GPa}, \mathrm{D}_{\mathrm{Mg}-\mathrm{Fe}}=10^{-20}$ at $1473 \mathrm{~K}, 10^{-17.6}$ at $1873 \mathrm{~K}$, and $10^{-16}$ at $2273 \mathrm{~K}$, which are also far below the $7.9 \times 10^{-10}$ $\mathrm{m}^{2} / \mathrm{s}$ value inferred from the sample. Clearly metal-extrinsic volume interdiffusion cannot account for the rapid interdiffusion in GRV 022321. The very high temperatures reached by olivines in shock melt (Hu and Sharp, 2917) may correspond to the purely intrinsic diffusion regime, with higher $D_{0}$ and $\Delta H$ values (Chakraborty, 2010), but there is no experimental data available to test this hypothesis.

\subsection{Multiple diffusion mechanisms}

The microstructures observed in BSE images indicate the Mg-Fe interdiffusion was not uniform through the olivine. The initial olivine grains were relatively large single crystals, ranging from 10 s of $\mu \mathrm{m}$ to several hundreds of $\mu \mathrm{m}$. The BSE contrast shows 
dark branching structures that extend many microns inward from the olivine-ringwoodite interface and surround small islands of more fayalite-rich olivine. These dark features are depleted in fayalite content relative to the initial $\mathrm{Fa}_{23}$ olivine and the residual olivine remnants. Our TEM data from the olivine at the interface with ringwoodite show that it is nanocrystalline, with crystal sizes of 100-200 nm(Fig. 4). We suggest that these dark channels represent highly deformed nano-crystalline olivine that served as a conduit for rapid grain-boundary diffusion (Fig. 6). Deformation during shock compression transformed regions of the single crystal olivine into nanocrystalline aggregates through grain-size reduction. These highly deformed zones then provided high-diffusion pathways to accommodate the diffusion-controlled growth of ringwoodite. The activation enthalpy $(\Delta \mathrm{H})$ for grain-boundary interdiffusion is similar to that of metal-extrinsic interdiffusion, but the absolute rate, and therefore $D_{0}$, is about 3 orders higher for grain boundary interdiffusion (Holzapfel, et al., 2005). Although there is no experimental data to confirm our interpretation, we suggest that long-range Fe-Mg interdiffusion was possible during shock because of the combined effect of very high temperatures and enhanced diffusion rates through channels of highly deformed nano-crystalline olivine. Residual undeformed olivine fragments in the olivine cores have higher fayalite contents (up to $\mathrm{Fa}_{23}$ ) because they exchange $\mathrm{Fe}$ and $\mathrm{Mg}$ through bulk Fe-Mg interdiffusion. These two diffusion mechanisms are illustrated in Fig. 6, where rapid grain-boundary interdiffusion results in low compositional gradients whereas bulk interdiffusion results in steeper concentration gradients.

\section{Conclusions}

GRV 022321 chondrite is an example of a highly shocked chondrite that displays ahrensite-rich ringwoodite rims on olivine cores. Similar textures have been reported in Dofar 922 (Badjukov, et al., 2005), GRV 0052049 (Feng et al., 2011), and Asuka 09584 (Petarello et al, 2015), but are absent in most highly shocked $L$ chondrites. The observed microstructures indicate that the original $\mathrm{Fa}_{23}$ olivine transformed to $\mathrm{Fa}_{10}$ olivine and $\mathrm{Fa}_{46}$ ringwoodite within the olivine-ringwoodite two-phase loop by a solid-state diffusion-controlled growth mechanism driven by local chemical equilibrium between ringwoodite and olivine during shock. The observed heterogeneities in fayalite content $\left(\mathrm{Fa}_{10}\right.$ to $\left.\mathrm{Fa}_{23}\right)$ of the olivine indicate complex long-range $\mathrm{Fe}-\mathrm{Mg}$ interdiffusion through the olivine to maintain local equilibrium at the olivine-ringwoodite interface. The contrast variations in olivine core suggest that a branching network of low-Fa olivine acted as long-range high-diffusion pathways for Fe-Mg interdiffusion through highly deformed nano-crystalline olivine to accommodate the diffusion-controlled growth of ringwoodite.

\section{Declarations}

\section{Availability of data and material}

The datasets supporting the conclusions of this paper are present in this paper. Additional data related to this paper may be requested from the authors.

\section{Competing interests}

The authors declare that they have no competing interest.

\section{Funding}

This work was supported by the National Natural Science Foundation of China, Grant number 41272057, and 40872036.

\section{Authors' contributions}

ZX and XL proposed the topic, conceived and designed the study. XL, SZ and ZX carried out the experimental study and analyzed the data and helped in the interpretation. ZX and TS wrote the paper. All authors read and approved the final manuscript.

\section{Acknowledgement}


We acknowledge use of FIB-SEM and TEM at the Leroy Eyring Center for Solid State Science at Arizona State University. We also acknowledge the late Paul DeCarli for assistance with shock physics. This work was not supported by NASA grants to T. Sharp.

\section{References}

Acosta-Maeda, Scott TE, Sharma ERD, Misra SK, Anupam K囚2013囚. The pressures and temperatures of meteorite impact: Evidence from micro-Raman mapping of mineral phases in the strongly shocked Taiban ordinary chondrite. Am Min 98:859869.

Badjukov DD, Brandstätter F, Kurat G, Libowitzky E, Raitala J (2005). Ringwoodite-Olivine Assemblages in Dhofar 922 L6 Melt Veins. 36th Annual Lunar and Planetary Science Conference (abstract).

Beck P, Gillet P, El Goresy A, Mostefaoui S (2005). Timescales of shock processes in chondritic and martian meteorites. Nature 435:1071-1074.

Binns RA, Davis RJ, Reed SJB (1969). Ringwoodite, Natural (Mg,Fe) 2 SiO 4 Spinel in the Tenham Meteorite. Nature 221:943944.

Chakraborty S (2010). Diffusion Coefficients in Olivine, Wadsleyite and Ringwoodite. Reviews in Mineralogy \& Geochemistry 72:603-639.

Chakraborty S, Knoche R, Schulze H, Rubie DC, Dobson D, Ross NL, Angel RJ (1999). Enhancement of Cation Diffusion Rates Across the 410-Kilometer Discontinuity in Earth's Mantle. Science 283:362.

Chen M, El Goresy A, Gillet P (2004). Ringwoodite lamellae in olivine: Clues to olivine-ringwoodite phase transition mechanisms in shocked meteorites and subducting slabs. Proc Natl Acad Sci U S A 101:15033-15037.

Chen M, Sharp TG, El Goresy A, Wopenka B, Xie X (1996). The Majorite-Pyrope + Magnesiowüstite Assemblage: Constraints on the History of Shock Veins in Chondrites. Science 271:1570-1573.

Diedrich T, Sharp TG, Leinenweber K, Holloway JR (2009). The effect of small amounts of H $2 \mathrm{O}$ on olivine to ringwoodite transformation growth rates and implications for subduction of metastable olivine. Chemical Geology 262:87-99.

Du Frane WL, Sharp TG, Mosenfelder JL, Leinenweber K (2013). Ringwoodite growth rates from olivine with $\sim 75$ ppmw $\mathrm{H}_{2} \mathrm{O}$ : Metastable olivine must be nearly anhydrous to exist in the mantle transition zone. Phys Earth Planet Inter 219:1-10.

Farber DL, Williams Q, Ryerson FJ (2000). Divalent cation diffusion in Mg2SiO4 spinel (ringwoodite), $\beta$ phase (wadsleyite), and olivine: Implications for the electrical conductivity of the mantle. Journal of Geophysical Research Solid Earth 105:513-529.

Feng L, Lin Y, Hu S, Xu L, Miao B (2011). Estimating compositions of natural ringwoodite in the heavily shocked Grove Mountains 052049 meteorite from Raman spectra. Am Min 96:1480-1489.

Fritz J, Greshake A, Fernandes VA (2017). Revising the shock classification of meteorites. Meteorit Planet Sci 52(6):12161232.

Holzapfel C, Rubie D, Frost D, Langenhorst F (2005). Fe-Mg interdiffusion in (Mg,Fe)SiO ${ }_{3}$ Perovskite and lower mantle reequilibration. Science 09:1707-1710.

Hu JP, Sharp TG (2017). Back-transformation of high-pressure minerals in shocked chondrites: Low-pressure mineral evidence for strong shock. Geochim Cosmochim Acta 215:277-294.

Page 10/18 
Hua X, Huss G, Tachibana S, Sharp TG (2005). Oxygen, silicon, and Mn-Cr isotopes of fayalite in the Kaba oxidized CV3 chondrite: Constraints for its formation history. Geochim Cosmochim Acta 69:1333-1348.

Kerschhofer L, Rubie DC, Sharp TG, Mcconnell JDC, Dupas-Bruzek C (2000). Kinetics of intracrystalline olivine-ringwoodite transformation. Phys Earth Planet Inter 121: 59-76.

Kerschhofer L, Dupas C, Liu M, Sharp TG, Durham WB, Rubie DC (1998). Polymorphic transformations between olivine, wadsleyite and ringwoodite: mechanisms of intracrystalline nucleation and the role of elastic strain. Mineralogical Magazine 62 (5):617-638.

Kerschhofer L, Sharp TG, Rubie DC (1996). Intracrystalline Transformation of Olivine to Wadsleyite and Ringwoodite Under Subduction Zone Conditions. Science 274:79-81.

Langenhorst F, Poirier JP (2000). Anatomy of black veins in Zagami: clues to the formation of high-pressure phases. Earth Planet Sci Lett 184:37-55.

Mason B, Nelen J, White JS (1968). Olivine-Garnet Transformation in a Meteorite. Science 160:66-67.

Miyahara M, El Goresy A, Ohtani E, Nagase T, Nishijima M, Vashaei Z, Ferroir T, Gillet P, Dubrovinsky L, Simionovici A (2008). Evidence for fractional crystallization of wadsleyite and ringwoodite from olivine melts in chondrules entrained in shock-melt veins. Proc Natl Acad Sci U S A 105:8542-8547.

Miyahara M, Ohtani E, El Goresy A, Ozawa S, Gillet P (2016). Phase transition processes of olivine in the shocked Martian meteorite Tissint: Clues to origin of ringwoodite-, bridgmanite and magnesiowüstite-bearing assemblages. Phys Earth Planet Inter 259:18-28.

Ohtani E, Kimura Y, Kimura M, Kubo T, Takata T (2006). High-pressure minerals in shocked L6-chondrites: constraints on impact conditions. Shock Waves 16:45-52.

Ohtani E, Kimura Y, Kimura M, Takata T, Kondo T, Kubo T (2004). Formation of high-pressure minerals in shocked L6 chondrite Yamato 791384: constraints on shock conditions and parent body size. Earth Planet Sci Lett 227:505-515.

Pittarello L, Ji G, Yamaguchi A, Schryvers D, Debaille V, Claeys P (2015). From olivine to ringwoodite: a TEM study of a complex process. Meteorit Planet Sci 50: 944-957.

Price GD, Putnis A, Agrell SO (1979). Electron petrography of shock-produced veins in the Tenham chondrite. Contrib Mineral Petrol 71:211-218.

Putnis A, Price GD (1979). High-pressure (Mg, Fe) ${ }_{2} \mathrm{SiO}_{4}$ phases in the Tenham chondritic meteorite. Nature 280:217-218.

Tomioka N, Miyahara M (2017). High-pressure minerals in shocked meteorites. Meteorit Planet Sci 52(9):2017-2039.

Sharp TG, Lingemann CM, Dupas C, Stöffler D (1997). Natural occurrence of MgSiO3-ilmenite and evidence for MgSiO3perovskite in a shocked $L$ chondrite. Science 277: 352-355.

Sharp TG, DeCarli PS 2006. Shock effects in meteorites. In: Lauretta DS, Jr HYM (Eds.), Meteorites and the Early Solar System II. University of Arizona Press, pp. 653-677.

Sharp TG, Xie Z, DeCarli PS, Hu J (2015). A large shock vein in L chondrite Roosevelt County 106: Evidence for a long-duration shock pulse on the L chondrite parent body. Meteorit Planet Sci 50:1941-1953.

Stöffler D, Keil K, Scott ERD (1991). Shock metamorphism of ordinary Chondrite meteorites. Geochim Cosmochim Acta 55:3845-3867.

Page $11 / 18$ 
Weisberg MK, Smith C, Benedix G, Herd CDK, Righter K, Haack H, Yamaguchi A, Aoudjehane HC, Grossman JN (2009). The Meteoritical Bulletin, No. 96, September 2009. Meteorit Planet Sci 44:1355-1397.

Xie X, Minitti ME, Chen M, Mao Ho-K, Wang D, Shu J, Fei Y (2002). Natural high-pressure polymorph of merrillite in the shock veins of the Suizhou meteorite. Geochim Cosmochim Acta 66:2439-2444.

Xie Z, Sharp TG (2004). High-pressure phases in shock-induced melt veins of the Umbarger L6 chondrite: Constraints of shock pressure. Meteorit Planet Sci 39:2043-2054.

Xie Z, Sharp TG (2007). Host rock solid-state transformation in a shock-induced melt vein of Tenham L6 chondrite. Earth Planet Sci Lett 254:433-445.

Xie Z, Sharp TG, DeCarli PS (2006a). Estimating shock pressures based on high-pressure minerals in shock-induced melt veins of L chondrites. Meteorit Planet Sci 41:1883-1898.

Xie Z, Sharp TG, DeCarli PS (2006b). High-pressure phases in a shock-induced melt vein of the Tenham L6 chondrite: Constraints on shock pressure and duration. Geochim Cosmochim Acta 70:504-515.

Xie Z, Li X, Sharp TG, De Carli PS (2012). Shock-induced ringwoodite rims around olivine fragments in melt veins of Antarctic chondrite GRV022321: Transformation Mechanism. 53rd Lunar and Planetary Science Conference, p. 2766.

\section{Figures}




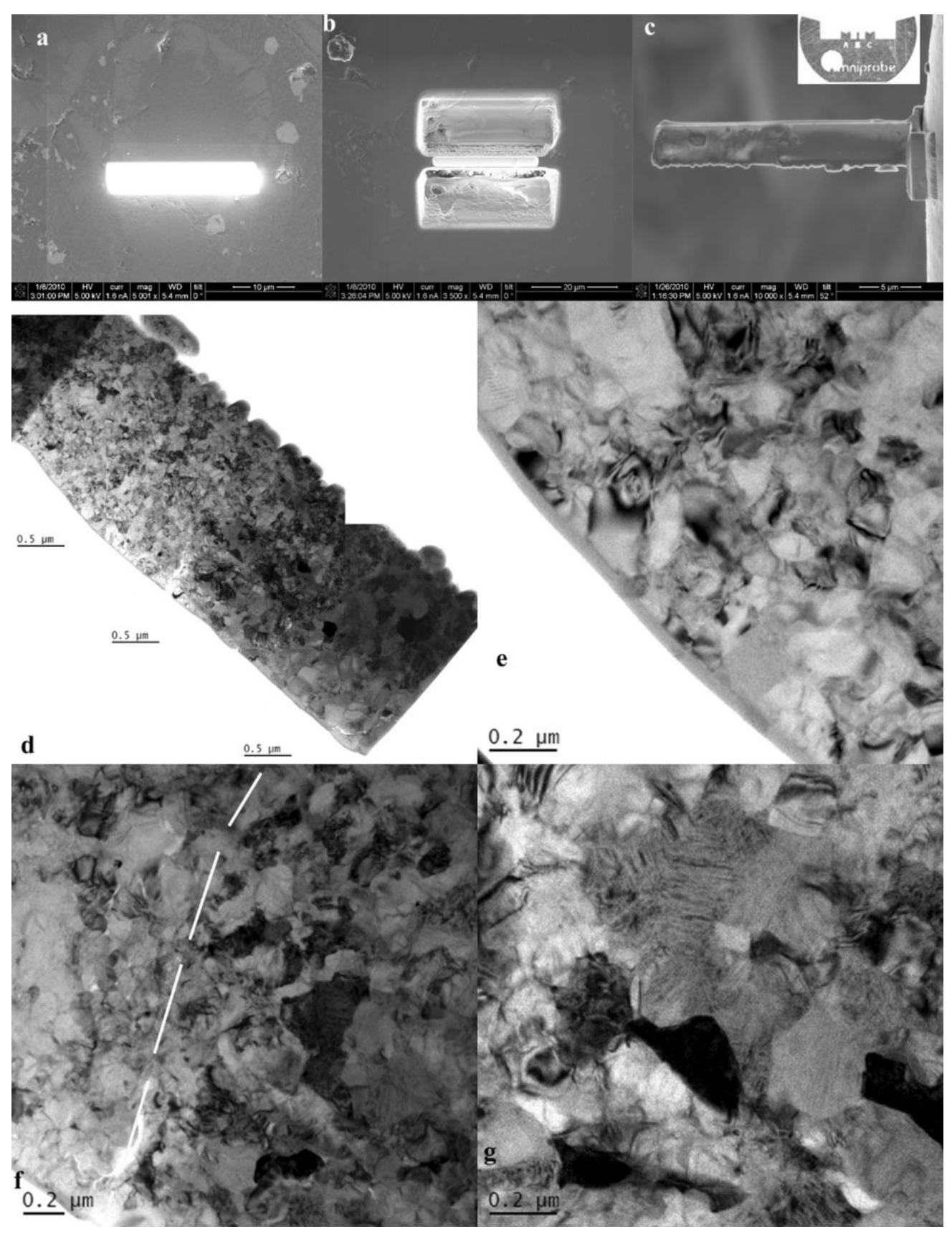

\section{Figure 1}

a) Optical micrograph of GRV 022321 chondrite under plane light showing one black vein in NE direction. b) BSE image of a shock-induced melt vein of GRV 022321 in square of Fig.1a. c) BSE image showing the locations of Fig. 2a and Fig.3, and FIB location in Fig.4. d) BSE image showing one big olivine clast entrained in the quenched melt-vein with a bright ringwoodite (rw) rim on a relatively dark olivine (ol) core, which displays a texture of dark channels surrounding islands of lighter-contrast olivine. 


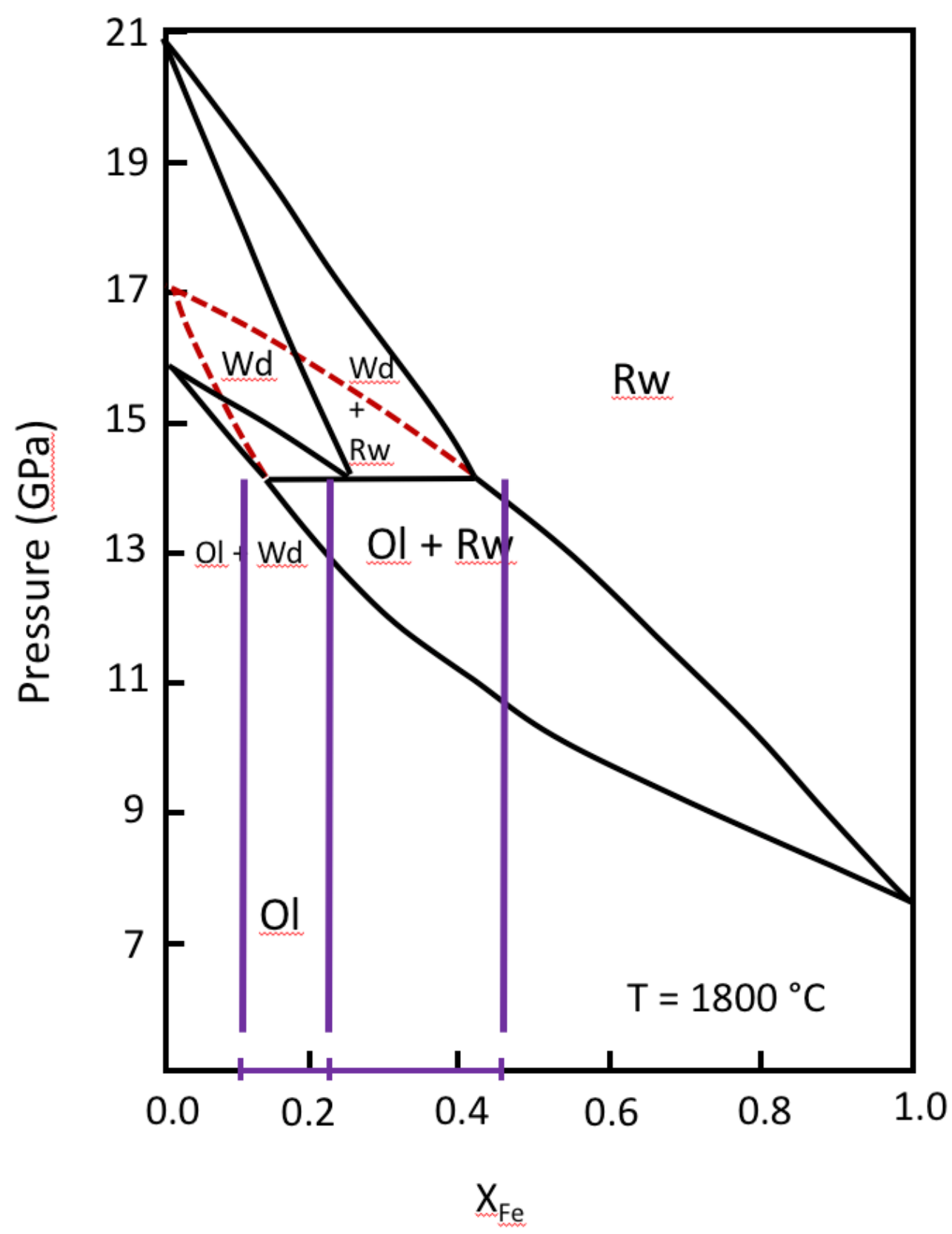

Figure 2

Raman spectra and measurement locations illustrated on BSE images. a) BSE image showing the location of 7 Raman measurement spots with 1,2,5,6 from bright rims and points 3,4,7 from the dark core. b) Raman spectra with signatures of ringwoodite (796 cm-1 and $846 \mathrm{c}-1)$ olivine ( $820 \mathrm{~cm}-1$ and $854 \mathrm{~cm}-1)$, and mixtures of the two. c) BSE image of the partially transformed olivine shown in Fig1d, illustrates the positions of five Raman measurement spots and two mapped regions (ak = akimotoite, rw = ringwoodite, ol = olivine) d) Raman spectra from 5 points in Fig.2c showing characteristic peaks of ringwoodite, olivine, and wadsleyite. 

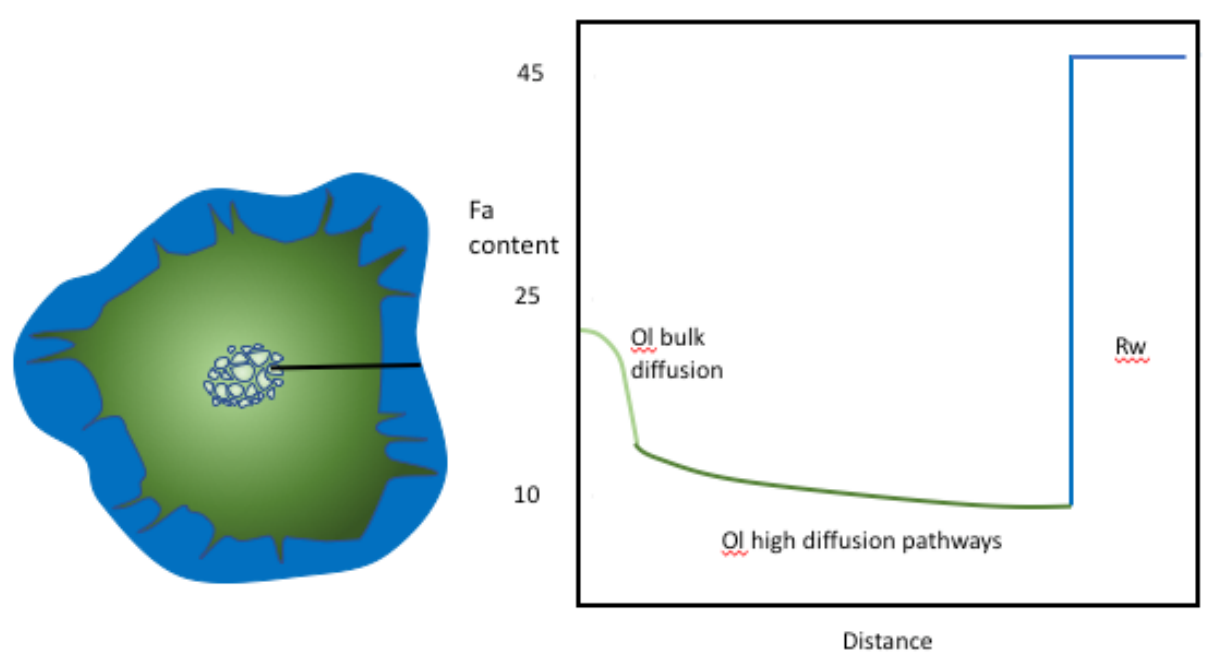

\section{Figure 3}

Fa values across one olivine fragment in melt vein of GRV 022321 chondrite. Upper BSE image showing ten EMPA points in red from rim to rim. EMPA data profile in bottom shows the fayalite ( $\mathrm{Fa}$ ) values of each point vertically corresponding to the point in upper BSE image. 

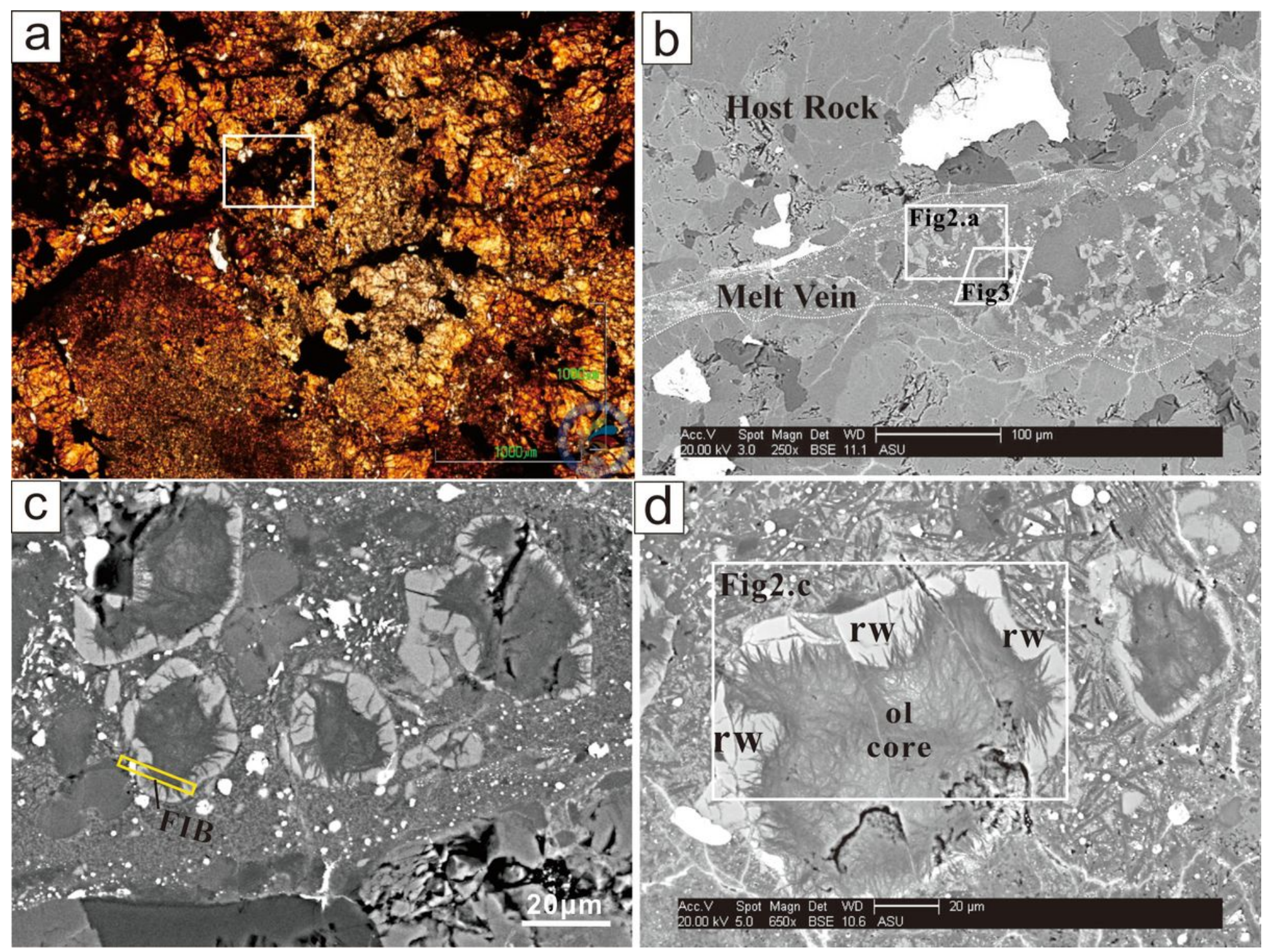

Figure 4

FIB-TEM results. a) FIB-SEM image showing Pt strip deposited across the transformed olivine shown in Fig. 1c. b) SEM image of the excavated FIB section. c) SEM image of the finished FIB foil mounted on a FIB-TEM half grid (inserted image). d) Brightfield (BF) TEM map of the FIB foil across the olivine (upper left) - ringwoodite (lower right) interface. e) BF image of polycrystalline olivine made up of 100-200 nm variably oriented crystallites. f) BF image of the boundary between nanocrystalline olivine and ringwoodite with a dashed line indicating the approximate location of the interface. g) BF image of polycrystalline ringwoodite rim, showing larger crystallites $(200-800 \mathrm{~nm})$ with contrast characteristic of stacking faults on $\{110\}$. 

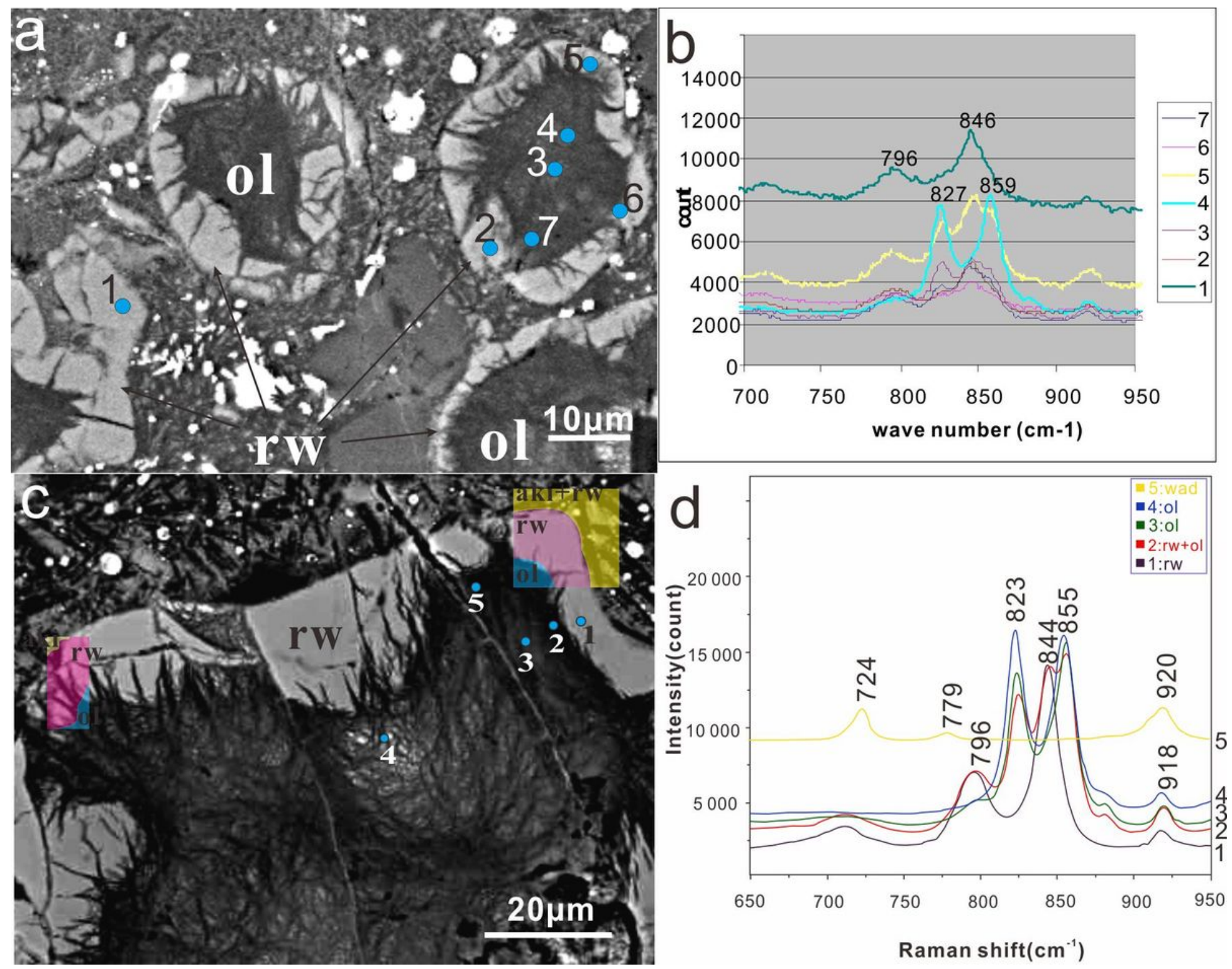

Figure 5

Pressure-composition phase diagram for Mg2SiO4-Fe2SiO4 at $1800^{\circ} \mathrm{C}$, after Fei et al. (1991) and Katsura and Ito (1989), showing olivine-wadsleyite-ringwoodite equilibria. We used the $0.4 \mathrm{GPa} / 100^{\circ} \mathrm{C} \mathrm{P} / \mathrm{T}$ slope of the olivine-ringwoodite equilibrium (Katsura and Ito, 19889) to shift from 1600 to $1800{ }^{\circ} \mathrm{C}$. The red dashed lines represent the metastable extension of the olivineringwoodite two-phase loop, which is shown to illustrate the full range of olivine-ringwoodite equilibrium. The compositions of coexisting core olivine (Fa23), rim ringwoodite (Fa46) and coexisting rim olivine (Fa10) are shown by the vertical purple lines. This range of compositions is slightly wider than the width of the olivine-ringwoodite loop at the boundary of wadsleyite stability (OI = olivine; $\mathrm{Rw}$ = ringwoodite; $\mathrm{Wd}$ = wadsleyite). 

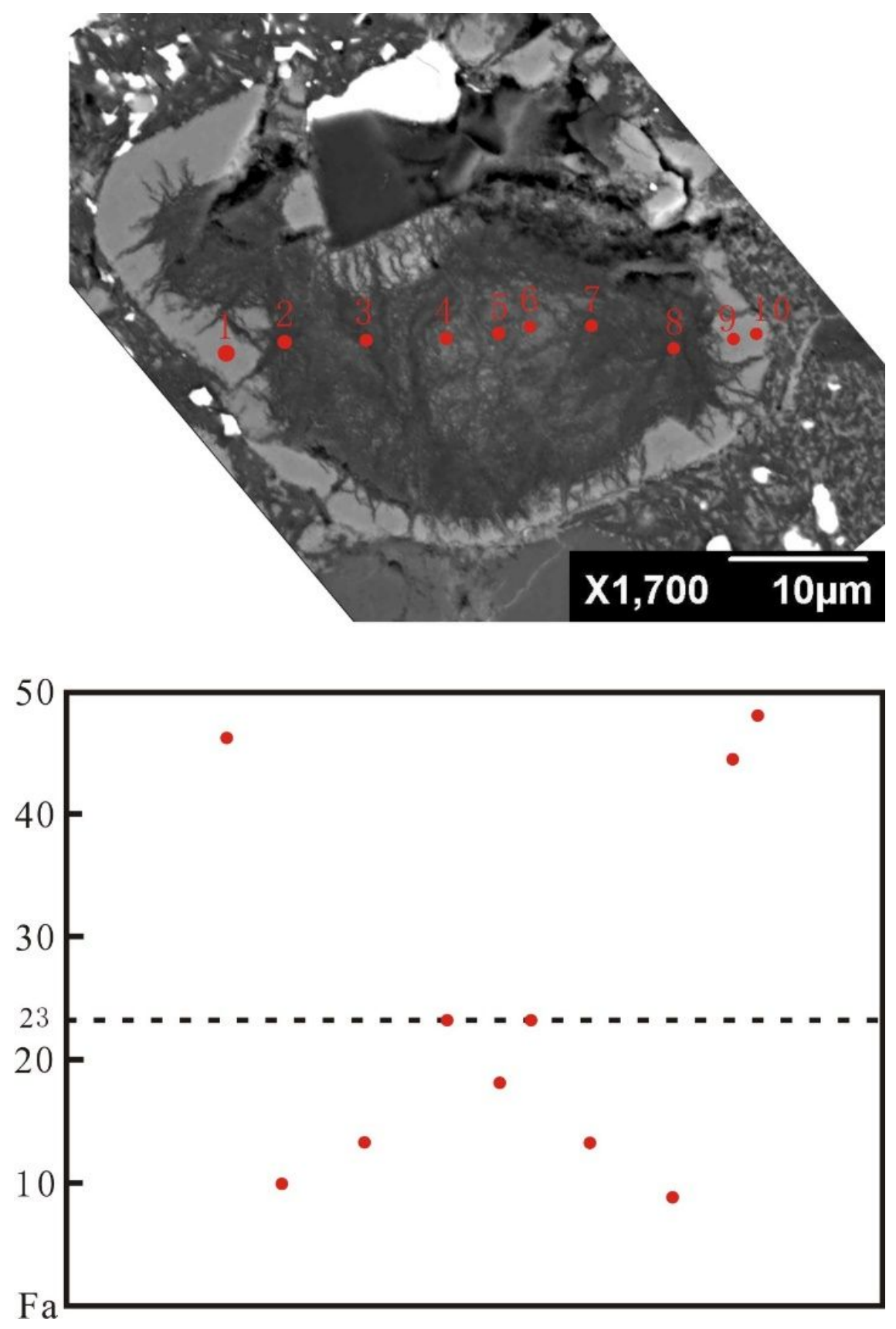

\section{Figure 6}

Schematic illustration of a partially transformed olivine fragment with a fayalite-rich (Fa46) ringwoodite rim, surrounding a heterogeneous olivine core. The fayalite content of the olivine is illustrated by gradient in green color, with the darkest green corresponding to Fa10 and the light-toned olivine islands in the center having a composition (Fa23) similar to the host rock. Ol=olivine, $\mathrm{Rw}=$ ringwoodite, $\mathrm{Fa}=$ fayalite.

\section{Supplementary Files}

This is a list of supplementary files associated with this preprint. Click to download.

- abstractimage.tif 